\title{
A Imagem como Estímulo no Processo de Imersâo e a Memória como o Regente no Trabalho do Ator ${ }^{1}$
}

The Image as a Stimulus in The Process of Immersion and Memory as Ruler at Work Actor

Priscila Silva da Rosa ${ }^{2}$ 


\section{Resumo}

O presente artigo relata 0 processo artístico experimental teórico-prático desenvolvido no ano de 2013, referente à montagem do conto "O Espelho", da obra Primeiras Estória, de João Guimarães Rosa. Este processo artístico experimental se propôs a investigar a relação do termo memória, de Henri Bérgson, em seu ensaio "Matéria e Memória" (1999), para tanto, são utilizadas as fotografias de Brooke Shaden ${ }^{3}$ como principal estímulo para a criação com a imagem fotográfica nesse processo. Portanto, com esse relato busca-se poder dividir com o leitor o que o laboratório prático e os ensaios possibilitaram ao espetáculo e, principalmente, ao trabalho da atriz.

Palavras-Chave: Processo artístico; Investigação; Memória.

\section{Abstract}

This article reports the experimental artistic process developed theorical andpactical in 2013, referent to the montage of the short story "O Espelho", from "Primeiras Estórias, by João Guimarães Rosa. This experimental artistic process proposed to investigate the relation of the memory term, of Henri Bérgson, in his essay "Matéria e Memória" (1999), Brook Shaden's photography are used as main stimulant in this process. Therefore, with this report we try to share with the reader what the practical laboratory and the rehearsal enabled to the spectacle and, mainly, to the actress' work.

Keywords: Contemporary dance; memory; body; video.

ISSN: 1808-3129

\footnotetext{
${ }^{1}$ Artigo elaborado a partir do processo de criação de um espetáculo solo vinculado ao Curso de Artes Cênicas com Habilitação em Interpretação, orientação do Professor Paulo Márcio Pereira, Universidade Federal de Santa Maria 2 Acadêmica do curso de Bacharelado em Interpretação, do Departamento de Artes Cênicas, na Universidade Federal de Santa Maria.
}

Brasil pri_medeia@hotmail.com

${ }^{3}$ Brooke Shaden é uma artista plástica norte-americana, que se destacou no campo das Artes Visuais por seu trabalho com colagem na fotografia. 


\section{Além da Imagem:}

No ensaio, "Matéria e memória” (1999), o filósofo pós-estruturalista Henri Bergson aponta a relação da criação por meio das imagens com a vivência do ator, ou seja, com as suas vivências e memórias corporais e mentais do ator. O processo de relação da imagem com a memória ficou conhecido, por meio de Bergson, como imagem-lembrança. Esse termo imagem-lembrança utilizado pelo pensador, pensando na prática elaborada nesse projeto, do que a matéria, definida por autor como conjunto de imagens, que percebida por "alguém" e da associação que "esse alguém", faz da imagem com o seu passado. Bergson destaca que para reconhecermos o curso de nosso passado e da imagem-lembrança, percebida localizada e presente, é preciso que haja um esforço em direção a essa imagem, para que sejamos então arremessados ao passado:

"Por ela [imagem-lembrança] se tornaria possível o reconhecimento inteligente, ou melhor, intelectual, de uma percepção já experimentada; nela nos refugiaríamos e todas as vezes que remontamos, pra buscar aí uma certa imagem, a encosta de nossa vida passada". (BERGSON, pag.62).

Sendo assim, entende-se a imagem, nesse processo, como um elemento de estímulo e inerente, pois entende-se que o meio de percepção e como um meio de criação, que pode potencializar a união da experiência e de lembrança sensório-corporal da atriz ao seu trabalhvo de estruturação do espetáculo.

Ademais, Bergson diz que não há percepção relacionada com uma memória que não esteja diretamente conectada a uma lembrança: "Na verdade, não há percepção que não esteja impregnada de lembranças. Aos dados imediatos e presentes de nossos sentidos misturamos milhares de detalhes de nossa experiência passada" (BERGSON, 1999, p.33). Pensando então, nessa do filosofo o professor Alexandre da Silva, estudioso do processo de criação por imagens, afirmará que:

\footnotetext{
"Considerando o nosso corpo e suas relações com a matéria, e aqui destacamos matéria como o conjunto de imagens que nos cercam, a memória é uma espécie de regente de todo o processo" ao perceber a memória como o regente do processo, temos então ativos nesse período o passado e o presente restringindo a nossa "interpretação" (Da SILVA, PELLENZ, ,p.2).
}

Pensando nisso, segundo da Silva, pode-se entender a imagem como memória no trabalho do ator, pois é a partir da imagem que o individuo se relaciona socialmente.

Notou-se que, a partir do processo gerado, entre a criação das formas e transformação dessas em partituras de ação, foram criados movimentos, e que em pequenas medidas eram referentes a situações passadas. Esses signos se transformaram em uma série de ações e que provocavam a memória do ator, podendo ser relacionado, ao que fora dito no tópico anterior, sobre a imagem estar ligada ao passado do indivíduo. Chega-se a uma conclusão, por intermédio do ensaio de Bergson, que a memória é praticamente inseparável da percepção, pois ela intercala o passado e o presente, condensa também numa intuição única.

Ademais, o autor afirma que a partir do momento em estabelecemos essa re- 
lação com a matéria ${ }^{4}$ é possivel que pensando na imagem tendo uma ligação direta com a memória, estamos sempre reconstruindo a todo instante o nosso passado e que a percepção distinta, na verdade, é como um círculo fechado, onde imagem- percepção dirige-se ao espírito e a imagem-lembrança estabelecem uma ligação.

\section{Olhar é Sempre Ver mais do que Se Ve5: Prática e Processo.}

O espetáculo solo "O Espelho" foi a público no dia 7 de janeiro de 2013, no Anfiteatro Caixa Preta em Santa Maria, Rio Grande do Sul. Esse fez parte do meu processo individual nas disciplinas de Interpretação I e II, Laboratório de Orientação V e VI, do Curso de Artes Cênicas Bacharelado com Habilitação em Interpretação, com orientação do Prof. Paulo Mário Pereira, na Universidade Federal de Santa Maria.

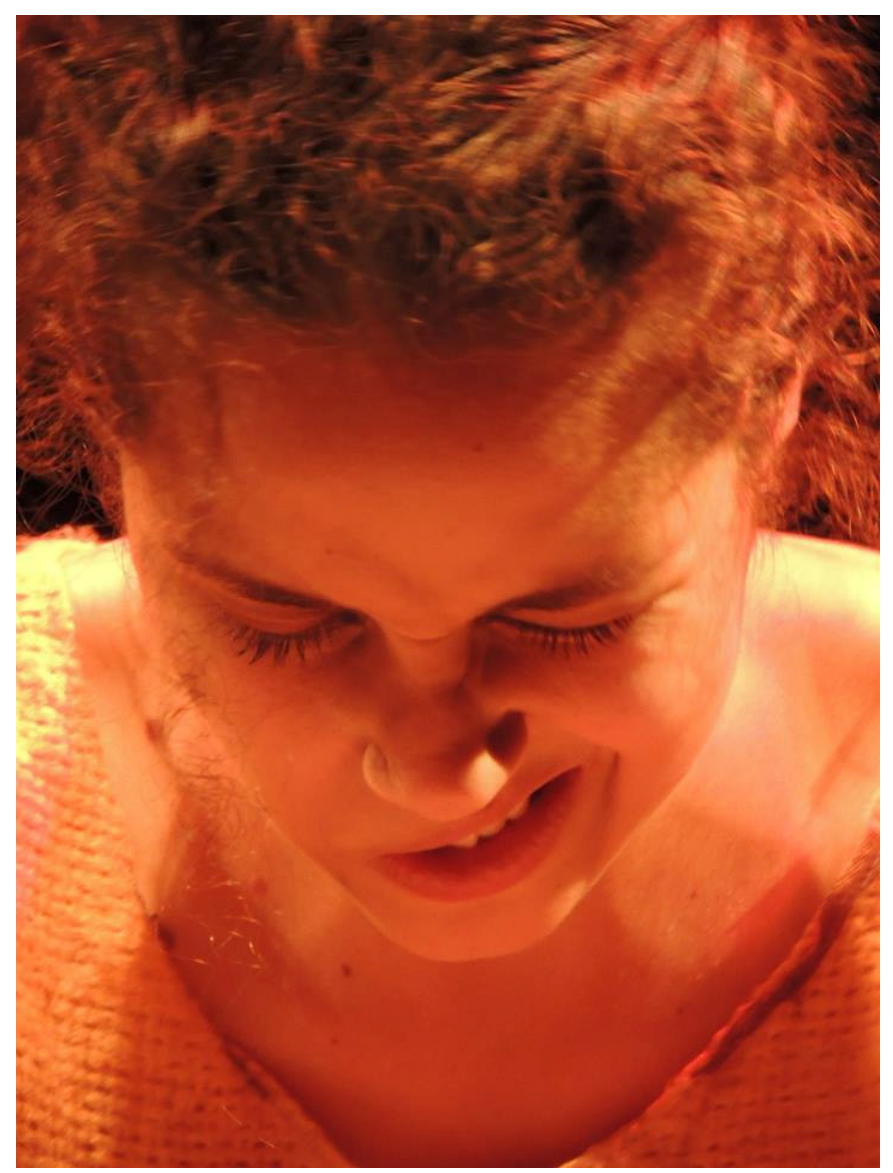

FIG.1 Espetáculo solo "O Espelho" / Créditos: Paulo Márcio Pereira

O espetáculo, assim como o conto "O Espelho"6, de autoria do escritor brasileiro Guimarães Rosa, de tema metafísico, transcendente, não é uma narrativa com história. Esse traz seu narrador em primeira pessoa, que diante de um espelho, discute mistérios, crenças populares e o fato do ser humano não passar de uma metáfora.

${ }^{4}$ Matéria é tratada nesse caso como imagem, segundo da Silva.

${ }^{5}$ MERLEAU-PONTY, Maurice. O Visível e o Invisível. Trad. José Artur Gianotti e Armando Mora d'oliveira. São Paulo: Editora Perspectiva, tradução 1971. 6 Este conto apresenta um aspecto que o destaca em relação aos demais do livro Primeiras Estórias: sua linguagem é erudita, carregada de termos científi- cos e filosóficos, numa formalidade que se afasta do caráter oral dos outros 20 textos, significando o fascínio exercido pelo espelho sobre cientistas e filósofos de todos os tempos. Em "O Espelho", predominou o aspecto esotérico, quando a obra apresenta vivamente retratos de pobreza, exclusão e abandono a que são entregues os habitantes do sertão. 
Para tanto, o principal estímulo para a criação foram imagens fotográficas de autoria da artista Brooke Shaden. O início meu processo criativo se deu com a busca por imagens para a criação de partituras de ação, paralelamente, à busca por reflexões teóricas. O acervo do laboratório prático contou com cerca de quarenta fotografias da artística visual Shaden, elas não estabeleciam uma relação direta com o conto e foram escolhidas de modo empírico.

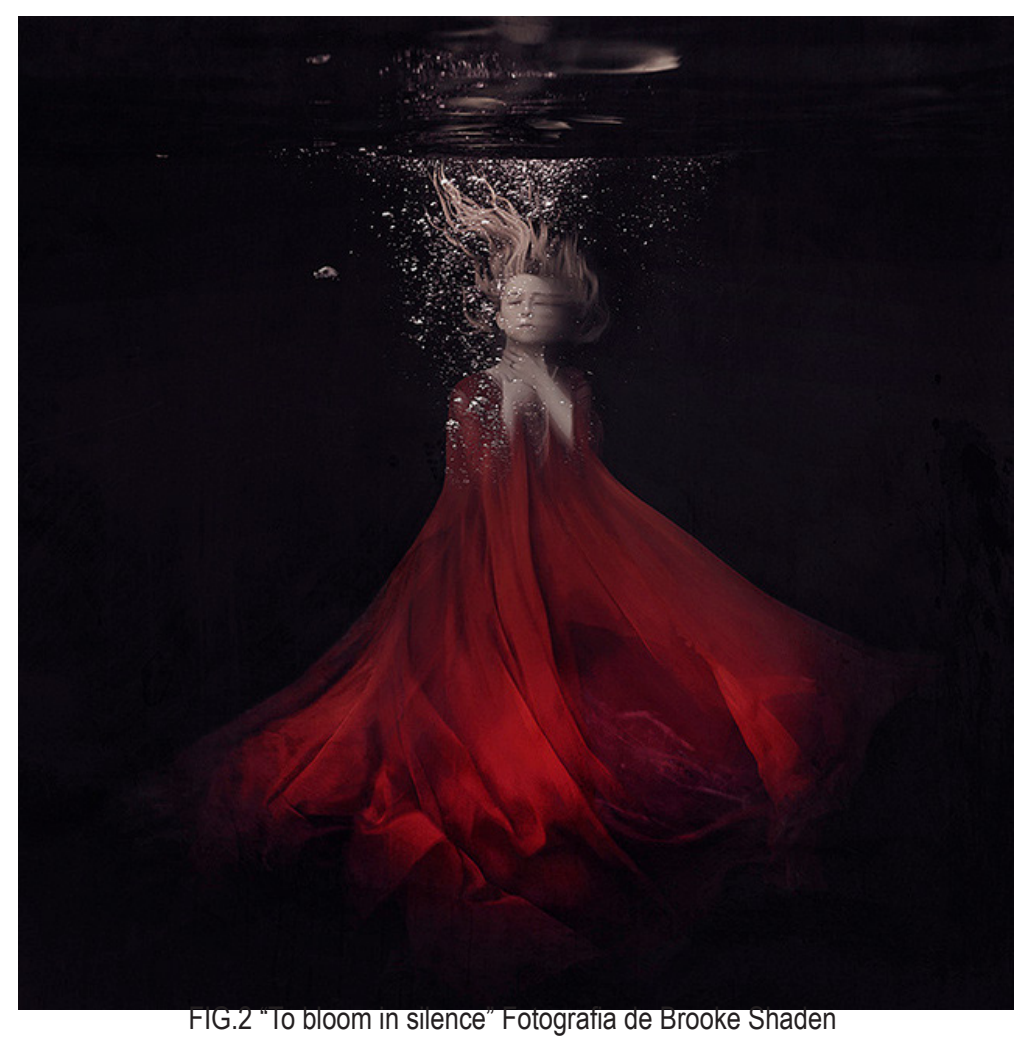

No meu primeiro contato com o acervo de imagens, do início até meados da esteia, procurei experimentar o que elas sugeriam, enquanto: ação, repetição, imitação ou até mesmo variação de velocidades, ou de níveis, vale ressaltar que o mesmo processo se deu com as palavras do texto. Pensando na minha prática e na relação dessa com o ensaio do pós-estruturalista, relacionada à memória, eu entendo que essa reflexão teórica se aplica a essa prática, porque me permite compreender e relacionar o papel da percepção e da memória nesse processo de criação e no meu trabalho de atriz. Entendo a memória como lembrança, como corpo que em laboratório e cena cria e recria, que se "auto-cria" em toda e qualquer repetição.

Na segunda etapa, ainda referente à criação da estrutura do espetáculo, em vista das dificuldades com o vocabulário rico e rebuscado do conto e do pouco tempo para assimilação das camadas do texto, consequentemente, da experimentação corpóreo-vocal, procurei trabalhar com imagens e vídeos próximos ao texto. Junto ao acervo foi acrescido esse novo material, como por exemplo, a obra "A Persistência da Memória" 1931 de Salvador Dali e o documentário7 "A mimeses através dos espelhos de Machado de Assis e de Guimarães Rosa" onde o professor Thiago Figueredo analisa a presença do objeto espelho ao longo da história da literatura por meio da análise 
do conto "O Espelho" de Guimarães, na expectativa que esses novos elementos pudessem auxiliar no diálogo do texto com as ações já edificadas. Por fim, a partir desse novo momento e com novo fomento, o processo entrou em uma etapa de imersão total e aos poucos as ações anteriormente criadas ganharam uma nova vida, "novas cores".

O espetáculo foi a público no dia sete de janeiro de 2013, e a minha maior dificuldade foi em decorar o texto de modo fiel e cauteloso, justamente, por ser uma obra clássica. No decorrer dos ensaios e junto ao meu orientador, em muitas das vezes, me questionei quanto à recepção do público ao texto e ao meu trabalho. $\mathrm{Na}$ estreia, diante da complexidade do texto, alguns espectadores tiveram dificuldade em conseguir adentra no contexto da peça.

Sendo assim, diante desse relato, foi possível aprender de modo prático o quão árduo é o trabalho do ator, principalmente se tratando de um monólogo e com um texto de tamanha complexidade, e entendo que mais importante do que ter um espetáculo finalizado é o caminho que se percorre para chegar até a estreia. Em suma, esse processo artístico desde o seu início caracterizou-se por seguir um caminho experimental e esse me permitiu descobrir um método de trabalho e com ele estabelecer uma relação teórico-prático reflexiva e também do concreto (as fotografias, imagens, vídeo) e o virtual (memória) com as minhas lembranças.

6 Site do documentário "A mímesis através dos espelhos de Machado de Assis e de Guimarães Rosa": http://www.youtube.com/watch?v=LBW3i1XuYiw 


\section{Referencias Bibliográficas:}

BERGSON, H. Matéria e Memória. Ensaio sobre a relação do corpo com o espírito. São Paulo: Martins Fontes: 1999.

DA SILVA, A.R; PELLENZ, V. S. Três Durações: Nelson, Glauber e Bressane. Projeto de Pós-doutorado. Capes. Universidade de Paris 3.

DOS SANTOS LOPES, Melissa; DAHMA, Miguel. Quando a memória é uma arte - Primeiros rastros do conceito de memória encontrados na obra "A Preparação do Ator", de Stanislavski. VI. Congresso de Pesquisa e Pós-Graduação em Artes Cênicas, 2010.

GUIMARÃES, J. F., et al. O conceito de memória na obra "Matéria e Memória" de Henri Bergson.

SHADEN, Brooke. Site de galerias da fotografa. Disponível em: <http://brookeshaden.com/gallery/> Acessado em: 15 de mar. 2012.

\section{Bibliografia Consultada:}

GROTOWSKI, Jersy. Para um teatro pobre. São Paulo: Dulcina e Teatro Caleidoscópio, 2010.

MONTHERO, Wagner. Em processo: imagens e memória como materiais de criação no contexto do drama moderno. Revista Urdimento, Santa Catarina N.17, V.1, setembro de 2011. 